\title{
Based on Big Data, Household Indebtedness Restraining Consumption Escalation of Township Residents in China
}

\author{
Zefan Zhang ${ }^{1}$, Yan Zhang ${ }^{2}$ \\ ${ }^{1}$ Shenyang Institute of Technology, Fushun, China \\ ${ }^{2}$ Chengde Branch of Postal Savings Bank of China, Chengde, China
}

\begin{abstract}
:
The consumption culture and concepts of Chinese households have undergone dramatic changes along with the rapid development of the market economy, that consumption in advance and consumption in debt led by young consumer groups has gradually been recognized and accepted by the public, resulting in accumulated financial risks faced by households with high liabilities from fear of liabilities originally. Based on big data, this paper uses descriptive statistical analysis and related technical tests to conclude the reasons why the household indebtedness of the township residents restrains the escalation of household consumption by using sampling survey and quota survey, and proposes countermeasures to improve the financial literacy of the residents, strengthen the relevant business capabilities of the financial institutions, and improve the related legal policies by the government, with the aim of contributing to the government's ability to make and implement economic policies concerning steady growth in the township and town areas.
\end{abstract}

Keywords: Township residents, Big data, Household indebtedness, Consumption escalation.

\section{OVERVIEW OF HOUSEHOLD INDEBTEDNESS RESTRAINING ESCALATION OF CONSUMER CONSUMPTION}

\subsection{Definition of Household Indebtedness}

Household indebtedness, i.e. family loan funds, including all debts, bank loans, bills payable to non-family members by all family members, can be divided into short-term liabilities (current liabilities) and long-term liabilities depending on the length of due time or differentiated by their actual service cycles (payment cycles), e.g. by week, month, season or 
year. Not only that, household indebtedness can also be classified by the content of liabilities, such as loans, debts, taxes, payable. Indeed, household indebtedness decision-making has a complex and comprehensive impact on the households and the economic society, which requires family members to consider the advantages and disadvantages of each decision carefully and thoroughly. Nevertheless, moderate liabilities can help to improve the welfare of households: on the one hand, debt smoothes the consumption of families in different periods and improves the total utility level of families across periods; on the other hand, the financial leverage of debt can speed up the growth of family wealth.

\subsection{Definition of Household Consumption Escalation}

Resident consumption refers to the consumption of consuming materials and services through activities such as eating, clothing, culture and entertainment for people's survival and development. It can be divided into material consumption, labor consumption and spiritual and cultural consumption by content, and into living materials consumption, developing materials consumption and hedonic consumption by purpose [1]. The escalation of household consumption is a dynamic and unbalanced process, which has at least two dimensions: one is the escalation of consumption level and the other is the escalation of consumption structure. The main reason why residents can escalate their consumption level is that they have sufficient purchasing power to meet their other needs except the necessary savings demand with the continuous growth of disposable income. The escalation of the consumption structure is most intuitively manifested in the overall consumer expenditure of residents, with the emphasis on the decreasing proportion of low-grade consumer products compared with the increasing proportion of high-grade consumer products. Macro data shows that the level of disposable income per capita in China has been steadily increasing. From 2000 to 2019, the average annual growth rate of disposable income per capita of rural household and township household is as high as $11.05 \%$ and $11.23 \%$, respectively, which is higher than the average growth rate of GDP in the same period. According to the data of the State Statistics Bureau, in 2019, the per capita consumption expenditure on food, tobacco and alcohol was 6,084 yuan, accounting for the largest proportion of per capita consumption expenditure, $28.2 \%$, increasing by $8.0 \%$; the per capita consumption expenditure on other consumer goods and services was 524 yuan, increasing by $9.7 \%$, accounting for the smallest proportion of per capita consumption expenditure, which was $2.4 \%$.

\subsection{Mechanism of Household Indebtedness Restraining Consumption Escalation}

The key to the research on the issue of consumer escalation is how to define and measure 
consumption escalation, for which domestic scholars mainly have two analytical frameworks, a "substance-service" analytical framework and a "survival-development-enjoyment" analytical framework [2]. Both of these analytical frameworks examine consumption escalation from a macro perspective and consider consumption escalation as a process of changing consumption structure. In real life, there is general agreement on the notion that a steady, predictable increase in income is a crucial factor in optimizing the consumer structure and promoting consumer escalation, and the inhibitory effect of consumer escalation is reflected by the influence of uncertain factors. To accurately determine this "extent", families must determine their current needs for credit as well as their future repayability, the possibility of various credit and corresponding channels, the level of interest, period, and limit, choose the appropriate type, quantity, and credit channels, and on that basis supplement debt behavior and, finally, rationally plan the consumption and investment of each credit and ensure that there is sufficient funding to repay in a timely manner. Once this expectation is exceeded, the household liabilities of residents will increase, directly restraining household consumption.

\section{A SURVEY ON THE CURRENT SITUATION OF HOUSEHOLD INDEBTEDNESS AND HOUSEHOLD CONSUMPTION OF TOWNSHIP RESIDENTS}

\subsection{Survey Methods and Samples}

To investigate the restraint of consumption escalation by household indebtedness in China, 10,000 questionnaires were designed and distributed to various communities in townships throughout the country, using quota sampling and random sampling. The respondents are township residents. The sample size of each community was determined by quota sampling method. Then, the random sampling method was used to select streets in each community for intercept interviews and to verify whether the respondents are household owners, to ensure the diversification of the respondents in line with the survey conditions and more comprehensive collection of information. The randomness and representativeness of the samples can be guaranteed due to the large scale of the survey and the use of completely random sampling. A total of 9,637 questionnaires were collected, with an overall recovery rate of $96.37 \%$, and a high overall recovery rate.

\subsection{Survey Sample Analysis}

Sample accuracy mainly depends on the size of sampling error, which can be controlled by sample size, i.e. sample quality. Therefore, on the basis of the existing sample size and its $95 \%$ confidence level, the absolute error of the target size can be calculated to determine whether the 
sample size meets the requirements. Since a combination of random sampling and quota sampling was used in this paper, the design effect deff of this sampling method can take the value of 1.0 , and the absolute error of proportional target size at $95 \%$ confidence is $\mathrm{df}=4.66 \%$. Tables I and II show that with a confidence level of $95 \%$ and a maximum allowable absolute error of $2 \%$, the minimum sample size required for simple random sampling was 2,401 , and 9,520 valid questionnaires were returned in this study, indicating that the sample size determined by this scheme meets the requirements and that this sample size has high precision. Cronbach's $\alpha$ coefficient was used to determine the reliability of the questionnaire. The questionnaire reliability statistics in Table III show that the calculation result of Cronbach's $\alpha$ coefficient is $\alpha=0.872$, indicating that the overall reliability of the questionnaire is high, and further data analysis can be made.

\section{TABLE I. Basic statistics of questionnaire}

\begin{tabular}{|c|c|c|c|}
\hline \multicolumn{4}{|c|}{ CASE SUMMARY } \\
\hline & & $\mathrm{N}$ & $\%$ \\
\hline \multirow{3}{*}{ CASES } & VALID & 9520 & 100 \\
\hline & EXCLUDED A & 0 & 0 \\
\hline & TOTAL & 9520 & 100 \\
\hline
\end{tabular}

TABLE II. Minimum sample size required for simple random sampling

\begin{tabular}{|l|l|l|l|}
\hline $\begin{array}{l}\text { MAXIMUM ALLOWABLE ABSOLUTE } \\
\text { ERROR } \\
\text { CONFIDENCE LEVEL }\end{array}$ & $\mathbf{9 0 \%}$ & $\mathbf{9 5 \%}$ & $\mathbf{9 9 \%}$ \\
\hline $1 \%$ & 6806 & 9604 & 16641 \\
\hline $2 \%$ & 1702 & 2401 & 4160 \\
\hline $3 \%$ & 756 & 1067 & 1849 \\
\hline $4 \%$ & 425 & 600 & 1040 \\
\hline $5 \%$ & 272 & 384 & 666 \\
\hline $6 \%$ & 189 & 267 & 462 \\
\hline $7 \%$ & 139 & 196 & 340 \\
\hline
\end{tabular}

Table III. Questionnaire reliability statistics

RELIABILITY STATISTICS

\begin{tabular}{l|lllll|}
\hline CRONBACH'S & CRONBACH'S ALPHA & BASED & ON & $\begin{array}{l}\text { ANUMBER } \\
\text { TLPHA }\end{array}$ & OF \\
STANDARDIZED ITEM & & & \\
\hline
\end{tabular}




\subsection{Analysis on household liabilities and consumption}

As shown in Fig 1, it is not difficult to find that $85.06 \%$ of the households in debt currently consume more than 50,000 yuan per year, which is higher than the number of households in debt at the same level, and the annual consumption level is higher than that of the non-indebted households, because they are more likely to increase development consumption and hedonic consumption in addition to meeting their basic survival needs. Most non-indebted households currently spend about 25,000 yuan per year on food, clothing, residential, transportation and communication, and medical and health care. However, indebted households currently consume significantly more at the same level each year, indicating that whether they are in debt or not, their consumption of family survival is basically the same as the per capita consumption level in China.

As shown in Fig 2, the average consumption level of most non-indebted households for household equipment, goods and services, education and cultural development category is between 10,000 and 25,000 yuan per year, of which the largest number of people with education and cultural consumption level is between 10,000 yuan and 25,000 yuan, reaching $49.43 \%$, which is $12.67 \%$ higher than the number of indebted households with the same consumption level. $11.49 \%$ of the indebted households currently spend more than 50,000 yuan on household equipment and services, an increase of 6.09\% over the number of indebted households with the same level of consumption, $19.54 \%$ over 50,000 yuan on education and culture, and a $14.14 \%$ increase over the number of indebted households with the same level of consumption, indicating that non-indebted households are more able to focus on their own consumption in the field of survival consumption than indebted households in order to meet their own development needs. 


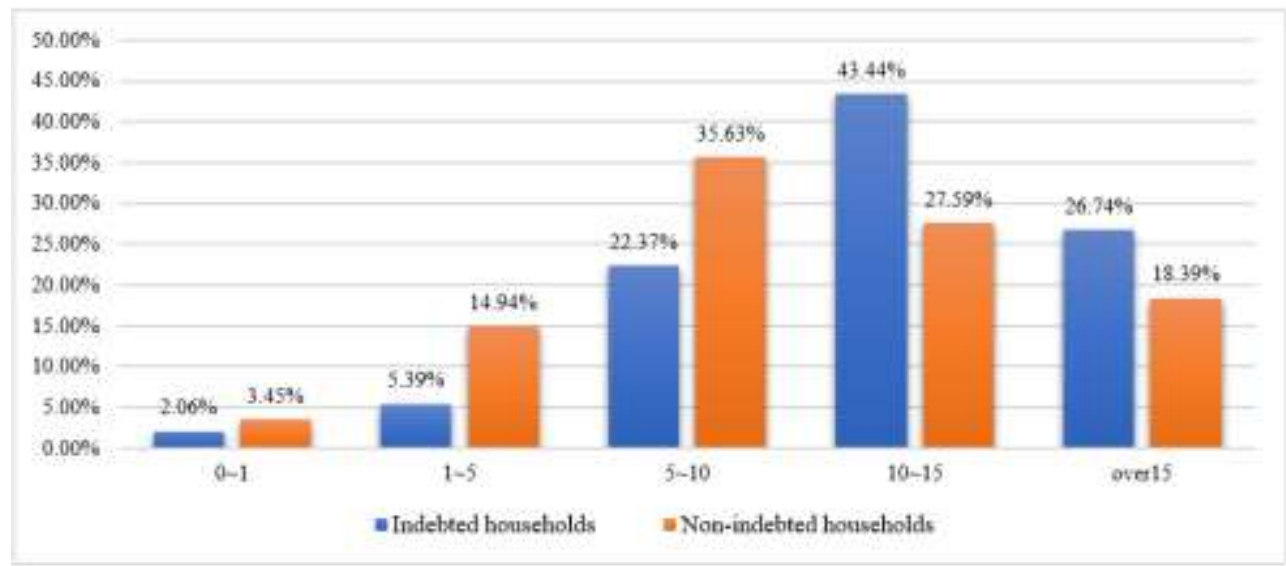

Fig 1: comparison of total consumption of indebted and non-indebted households (Unit: 10000 yuan)

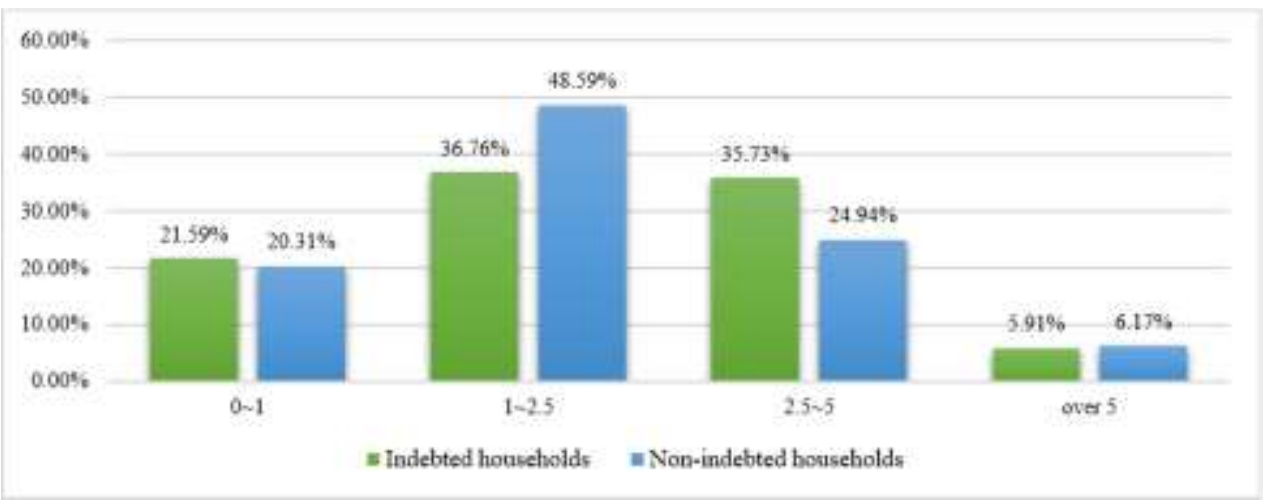

Fig 2: comparison of educational and cultural consumption between indebted and Non-indebted households (Unit: 10000 yuan)

\section{CAUSES FOR HOUSEHOLD INDEBTEDNESS RESTRAINING CONSUMPTION ESCALATION OF TOWNSHIP RESIDENTS IN CHINA}

\subsection{Lack of Financial Literacy of Residents}

Research shows that with the continuous improvement of financial literacy, the more likely the households are to make credit decisions beneficial to themselves, the better they can make use of the smooth lifetime consumption of credit market to improve the financial well-being of the family. Reasonable credit for households is not only conducive to the development of the 
family itself, but also to the healthy and stable development of credit market and real estate market in China [3]. In addition, increases in resident financial literacy promote resident family borrowing preferences, leverage of formal financial institutions such as banks to borrow, and planned repayment loans through financial institutions can alleviate resident liability pressures, reduce the need for relatives to borrow and civil borrowing, increase residents' consumption of other types, and promote escalation of resident consumption. At present, the demand for elderly consumption in our country has shown an expansion potential, but the development of elderly financial business associated with it has relatively lagged, which has restrained the continuous expansion of elderly consumption demand in our country and exerted a suppressive effect on the situation of elderly household consumption escalation.

\subsection{Inadequate Relevant Services Provided by Financial Institutions}

Compared with the credit consumption market of western developed countries, the development of consumer credit market in China is relatively short and lags behind. At the same time, there are fewer types of credit services and single financial institutions. According to the Standard for Loan Statistical Classification and Coding (Trial) published by the People's Bank of China, currently, consumer loans in China include four categories, namely, personal housing loans, personal automobile consumer loans, student loans and other consumer loans, among which the personal housing loans are the largest but cannot meet the residents' consumption in other aspects. Consumer credit is still mainly carried out by state-owned commercial banks, while other financial institutions have less involvement, resulting in many residents borrowing money through other means such as private loans to meet their current needs. The inadequate publicity of the services provided by the financial institutions has led to many residents not understanding the relevant financial business, which limits the judgment on their own debt ability and makes it easier for them to restrain the escalation of household consumption due to family liabilities. Moreover, the credit scale of financial institutions is too large to cause negative impact on the credit consumption market.

\subsection{Inadequate Government Policies}

The survey reveals that the rapid growth of household indebtedness has a significant inhibitory effect on household development and hedonic consumption, which hinders the consumption escalation of such households. Specifically, the increase of household liabilities has a significant inhibitory effect on the development and hedonic consumption of the indebted family, but has no significant negative impact on the survival and development and hedonic consumption of the indebted household. Although the ratio of liabilities to assets has increased, 
it has promoted family development and hedonic consumption to a certain extent, which indicates that moderate liabilities of indebted families will contribute to the escalation of household consumption. The rapid rise of housing prices is the main reason for the pressure of household liabilities caused by the purchase and construction of houses, but excessive rise will cause a series of people's livelihood problems, which requires the government to solve the real estate market problems, in order to prevent the excessive rise of housing prices, and achieve the healthy and stable development of the real estate market [4]. Increasing the income level of residents is not only the direct driving force for the escalation of consumption, but also what should be focused on the transformation of economic development mode in our country. But there are currently fewer policies on maintaining the income level of residents in China, most of whom do not have high income levels, making it difficult to achieve the escalation of consumption [5]. The level of market price and the ability of resident credit consumption are also important factors in restraining the escalation of resident household consumption. Therefore, the government should pay close attention to the change of commodity price level as well as the systematic and non-systematic risks in credit market so as to optimize the debt structure of resident households and guide them to use debt leverage reasonably and effectively.

\section{BASED ON BIG DATA, COUNTERMEASURES FOR IMPROVING HOUSEHOLD INDEBTEDNESS RESTRAINING CONSUMPTION ESCALATION OF RESIDENTS IN CHINA}

\subsection{Improving Financial Literacy of Residents}

First, residents should enhance their financial learning ability and form good consumption habits; secondly, they can communicate and study with neighbors with higher financial literacy through community activities to improve their financial literacy and cultivate high-grade life pursuit and healthy lifestyle. The good atmosphere of green consumption, healthy consumption and quality consumption should be created starting from the concept of mass consumption to create a positive social environment for consumption escalation. Increased financial literacy can lead residents to a more rational allocation of household assets and the rational use of household assets for basic survival, enrichment for investment, and backup of savings. In addition, improving the financial literacy of residents will also enable residents to seek help from financial institutions in a timely manner when they encounter financial problems, which can not only reduce the family's excessive debt, but also improve the family's awareness of credit consumption and participation in credit behavior. It is also beneficial for consumers to smooth their consumption for a lifetime through reasonable indebtedness and thus improve the 
family's financial welfare, and is also conducive to the healthy and stable development of the credit market.

\subsection{Enhancing Relevant Business Abilities of Financial Institutions}

The financial operations cannot be restricted to commercial banks only, but also in financial institutions such as insurance companies, trusts, and consumer finance companies with expansions from the basic housing, automobile and student loans to the fields of durable goods consumption, decoration and tourism throughout the people's livelihood, so that residents can participate in the financial activities of the whole people. Financial institutions should also strengthen the publicity of relevant businesses, carry out financial knowledge popularization business, improve residents' ability to identify financial risks, and at the same time strengthen customers' understanding of the institution to help residents improve their consumption ability and increase consumption escalation ability. Financial institutions should also properly control the scale of credit, mitigate the risk of consumer credit, ensure the positive role of consumer credit development in the overall economy, and prevent the negative effects of excessive consumer credit. Moreover, financial institutions should also raise the standards for credit issuance and prevent financial risks arising from excessive liabilities of low- and middle-income groups. On the other hand, they should reduce the support for housing liabilities of high-income groups, increase the utilization rate of their own funds, and avoid the support of family leverage, which will further widen the asset gap, promote the rational use of their own funds, and help residents upgrade their consumption capacity to a higher level.

\subsection{Gradually Improving the Relevant Government Policies}

The problem of household indebtedness of residents is mainly reflected in the housing liabilities, and the government should reasonably control the real-estate market, promulgate the implementation of housing price policies, and control the growth of the housing price within a reasonable range and so on. At the same time, the government needs to enforce the basic threshold limit of housing credit and control the uncoordinated development of housing credit and non-housing credit, not only to enable the healthy and stable development of the real estate market, but also to benefit the overall increase in the national consumption level. For residents without housing, the government should vigorously develop the housing rental market, especially the long-term rental market, so as to provide effective housing security for the low-income people through the housing security system, and reduce the pressure on them to obtain property rights housing through excessive debt. The government should make efforts to raise the income level of residents, reasonably allocate the cost of social security system 
between the government and individuals, control the individual payment level of social security for township residents to avoid the crowding-out effect of individual payment burden on their consumption of high-grade commodities, while strengthening the government's social security responsibilities and capabilities, fully playing the functions of social stabilizer and economic booster of the social security system, to promote the escalation of consumption among township residents. More than that, the government should also pay attention to price control, maintain stable price level, play a role of price leverage in guiding and adjusting the supply structure, further reduce the threshold of high-end commodity consumption by utilizing technical progress and market competition of suppliers in the fields of household durables, transportation and communication equipment, residential services, and achieve effective connection at the two ends of consumer supply and demand to lead the consumption of township residents to escalate.

\section{CONCLUSION}

Improving the situation in which household indebtedness restrains the escalation of household consumption requires concerted efforts from governments, financial institutions, residents. The government should implement relevant policies to effectively increase the disposable income of residents, establish a healthy real estate market, and establish a robust financial market system and social security system in China, and continue to explore improvements in relevant policies. Financial institutions should broaden relevant business, strengthen publicity, help residents improve consumption level and reduce the worries of residents and families. Residents themselves should improve their financial knowledge reserve capacity, strengthen their financial literacy, and raise their consumption level and ability in a scientific and correct way. This study provides a theoretical basis for the correct direction of development of consumer credit in China, and has great significance for improving the level of consumption of Chinese residents, promoting the healthy development of the consumer market, and promoting the escalation of the consumption structure.

\section{REFERENCES}

[1] Wei Y, Yang G, Yang MY (2017) Characteristics and Reasons of Consumption Escalation of Township Residents - Empirical Study from the Perspective of Space Spillover. Inquiry into Economic Issues (01):51-63.

[2] Jiang N (2019) Impact of Financial Knowledge on Household Indebtedness. Market Weekly (12):137-138.

[3] Ma XC, Song K (2019) Income Gap, Debt Status and Family Housing Asset Allocation. China Real Estate (24):19-28. 
[4] Pan M, Liu ZQ (2018) Can Families Leveraging Promote Consumption - Empirical Evidence from Micro-survey of Chinese Families. Journal of Financial Research (04):71-87.

[5] Wu WX, Wu K, Wang J (2018) Financial Literacy and Family Liabilities - Analysis Based on Micro-survey Data of Chinese Resident Families. Economic Research. 